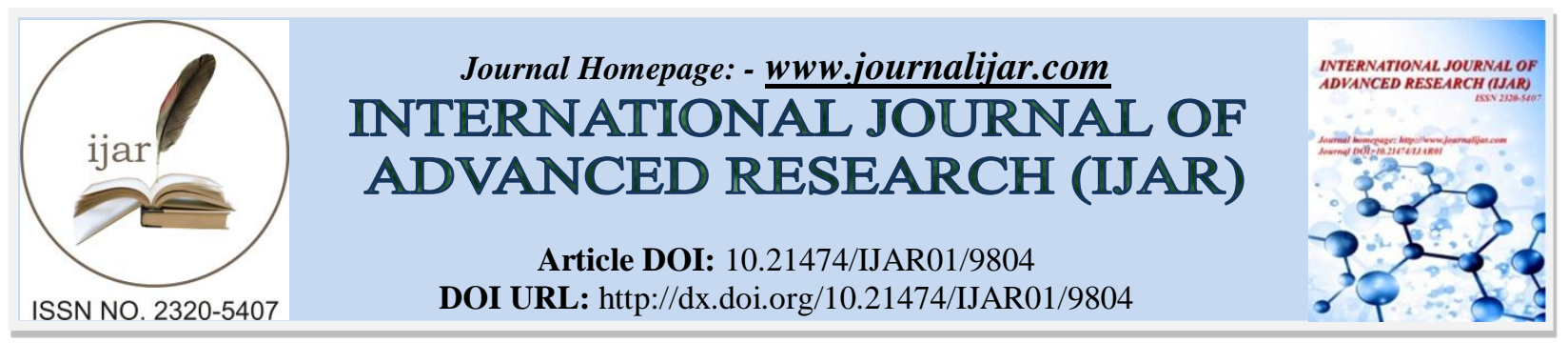

RESEARCH ARTICLE

\title{
LAPAROSCOPIC GASTRIC PLICATION COMPARED WITH SLEEVE GASTRECTOMY FOR MORBID OBESITY : A PROSPECTIVE RANDOMIZED STUDY.
}

Ashraf Goda, Hany Mohamed and Tamer. A. A. M. Habeeb.

Department of general surgery Zagazig University.

\section{Manuscript Info}

\section{Manuscript History}

Received: 02 August 2019

Final Accepted: 04 September 2019

Published: October 2019

Key words:-

Gastric plication, laparoscopic bariatric surgery, laparoscopic sleeve gastrectomy, morbid obesity.

\begin{abstract}
Background: Laparoscopic sleeve gastrectomy (LSG) involves resection of a significant portion of the stomach. Laparoscopic gastric plication (LGP) is a relatively alternative procedure similar to LSG, but without the need for gastric resection and low financial coast.

Patients and methods: Fifty two patients fulfilled the National Institutes of Health criteria and were assigned randomly to receive either LGP $(n=26) 19$ women and 7 men; mean age 40.15 7.35 (21 48) years and a mean BMI $46.96 \pm 4.30 \mathrm{~kg} / \mathrm{m}^{2}$ or LSG $(n=26) 17$ women and 9 men; mean age $39.73 \pm 8.53(20-50)$ years and a mean BMI $46.23 \pm 4.21 \mathrm{~kg} / \mathrm{m}^{2}$ by a block randomization method. Patients were studied in terms of postoperative weight loss, complications. Change of $\mathrm{HbA} 1 \mathrm{c}$ and hypertension.

Results: All procedures were completed laparoscopically. Follow-up was 12 months. The mean hospital stay was 2.5 (3-6) days for both groups. Postoperative complications occurred in 2 cases of minor leak and 3 cases of bleeding were detected after LSG and one case of bleeding and two cases of gastric stenosis following LGP. All patients experienced postoperative excess weight loss which was significantly better in the LSG group in terms of the change in BMI (mean 19.04 compared with 14.72 in LGP) and reduction of HbA1c (mean 1.3 compared with 0.6 in LGP).The improvement in hypertension was not significant.

Conclusion: LGP is feasible, safe, inexpensive and effective, but has an inferior weight-loss effect compared to LSG for morbidly obese patients with BMI above $40 \mathrm{~kg} / \mathrm{m}^{2}$.
\end{abstract}

Copy Right, IJAR, 2019,. All rights reserved.

\section{Introduction:-}

Obesity is a major health problem affecting over 1.7 billion people. A crude popular measure of obesity is the body mass index (BMI), a person with a BMI of 30 or more is generally considered obese. A person with a BMI equal to or more than 25 is considered overweight ${ }^{1}$.obesity is major risk factors for a number of chronic diseases, including diabetes mellitus, cardiovascular diseases and cancer. It is associated with significant co morbid conditions and reduced life expectancy. Since 1997, obesity has been officially recognized by the World Health Organization as a global epidemic ${ }^{2}$. 
There is a number of different surgical procedures are available for treatment of morbidly obese patients. These procedures create weight loss by two mechanisms of action: restriction and malabsorption ${ }^{1}$.Gastric restriction as laparoscopic sleeve gastrectomy, vertical banded gastroplasty, horizontal gastroplasty and laparoscopic adjustable gastric banding. Malabsorption as Jejunocolic bypass and jejunoileal bypass. Combination as Roux-en-Y gastric bypass and Biliopancreatic diversion ${ }^{3}$.

Laparoscopic sleeve gastrectomy (LSG) has gained increasing acceptance among bariatric surgeons and patients because of encouraging excess weight loss and resolution of co morbidities. Initially established as the first stage of 2nd stage bariatric approach, it is now used as a primary bariatric procedure because of documented excellent weight loss and an acceptable risk of complication. Advantages include the avoidance of implantable material, maintenance of gastrointestinal continuity, avoidance of malabsorption, and convertibility to other operations ${ }^{4}$.

\section{Patients and methods:}

52 cases of morbid obesity were prospectively randomized into two groups; each group is $(n=26)$ patients. (LGP) group underwent laparoscopic gastric plication include 19 women and 7 men their ages ranged from (21-48) with a mean age $(39.73 \pm 8.53)$ years and a mean BMI $(46.96 \pm 4.30) \mathrm{kg} / \mathrm{m} 2$. (LSG) group underwent laparoscopic sleeve gastrectomy their ages ranged from (20-50) with a mean age $(40.15 \pm 7.35)$ years and a mean BMI $(46.23 \pm 4.21)$ $\mathrm{kg} / \mathrm{m} 2$. in our unit of Zagazig University hospital From February 2015 to February 2018. The study had been previously approved by the Research Ethics Committee of the university. Informed consents were obtained. All patients provided a medical history including obesity, dietary history and co morbid diseases as diabetes mellitus and hypertension. Followed by a physical examination, full laboratory investigations, ultrasonography and upper GIT endoscopy. All patients were evaluated preoperatively according to the American Society of Anesthesiologists (ASA) scoring system.

\section{Inclusion criteria:}

Age of the patient is $20-60$ years old with BMI more than $40 \mathrm{~kg} / \mathrm{m}^{2}$ or BMI 35 with co-morbidity related to obesity and less than $60 \mathrm{~kg} / \mathrm{m}^{2}$.

\section{Exclusion criteria:}

BMI is $60 \mathrm{~kg} / \mathrm{m}^{2}$ or more, active peptic ulcer disease, hiatus hernia, sever esophagitis or gastro- esophageal reflux disease, Barrette's oesphagous and previous bariatric surgery. For details of trial profile, see the trial flow sheet (Fig. $1)$.

\section{Operative technique: \\ Laparoscopic gastric plication (LGP):}

With general anesthesia the patient was positioned in a 15 degree reverse Trendelenburg position with both arms placed in abduction and with a split leg position. The surgeon stood in between the legs, the camera operator stood on the right, and the assistant stood on the left of the patient.

Pneumoperitoneum was done using a Veress needle or Visiport according to BMI with a pressure setting of 14-15 $\mathrm{mm} \mathrm{Hg}$. A 5 trocar technique was used and the trocar placement was as follows: Two 12-mm ports were used; one was $20 \mathrm{~cm}$ below the xiphoid process and slightly to the left of the midline for 30 degree camera and one at right midclavicular line for the left surgeon's hand. Three 5-mm ports were used; one located just below the xiphoid process for liver retraction, one at the left anterior axillary line just below the costal margin for the assistant instrument, and one at the left midclavicular line for the surgeon's right hand.

Using the Harmonic scalpel dissection of the gastric greater curvature was started at a point $4-6 \mathrm{~cm}$ proximal to the pylorus and then extended upwards until the angle of Hiss $2 \mathrm{~cm}$ away of oesophageous. Careful dissection of any posterior gastric adhesion was done. Pouch calibration was achieved by passing a 36-Fr orogastric bougie toward the pylorus. Plication was commenced by applying 2 rows of extra mucosal sutures. The first row was composed of interrupted stitches (Fig. 2). This was followed by a second row of running 2-0 V-loc sutures (Fig. 3). Intraabdominal drain was inserted.

\section{Laparoscopic sleeve gastrectomy (LSG):}

The type of anesthesia, position of the patient, pneumoperitoneum, trocar placement, dissection of the gastric greater curvature and pouch calibration were the same as LGP. Stapling of the stomach was started $4-6 \mathrm{~cm}$ from the pylorus 
by using a green load first then we used a gold loads to rest of stomach (Fig. 4) then we used a blue load at the funds (Fig. 5). The specimen of the stomach was then removed. The leak test was routinely performed with methylene blue. Intra-abdominal drain was inserted.

\section{Postoperative course:}

Oral clear fluids were started after 24 hours of operation. Protons pump inhibitor (Pantoprazole) 40mg was given IV once daily early postoperative and continued for one month after discharge orally $40 \mathrm{mg}$ once daily before eating. 3 rd generation cephalosporin intravenously injection was continued postoperatively for additional 2 days. Patients continued on clear fluids for one week (sugar free) as water and apple juice. Then full fluids during the second week (sugar free) as milk and any juice. Then soft food during the third week. Then began regular food after 1st month with supplementation of calcium $1000 \mathrm{mg}$, vitamin D $800 \mathrm{IU}$, vitamin B12 $1000 \mathrm{mcg}$. All taken orally once daily.

\section{Follow up:}

Subsequent follow-up visits were scheduled every week for one month then monthly for three months, then after six months, and one year after surgery. Evaluation of the patients in post-operative visits included: wound care, documentation of weight loss, testing for postoperative nutritional deficiencies and diagnosis of any post-operative complication. Weight loss was assessed by decrease in BMI and percentage of excess body weight loss. Assessment of HbA1c change in diabetic patients and evaluation of blood pressure improvement in hypertensive Patients by endocrinologist.

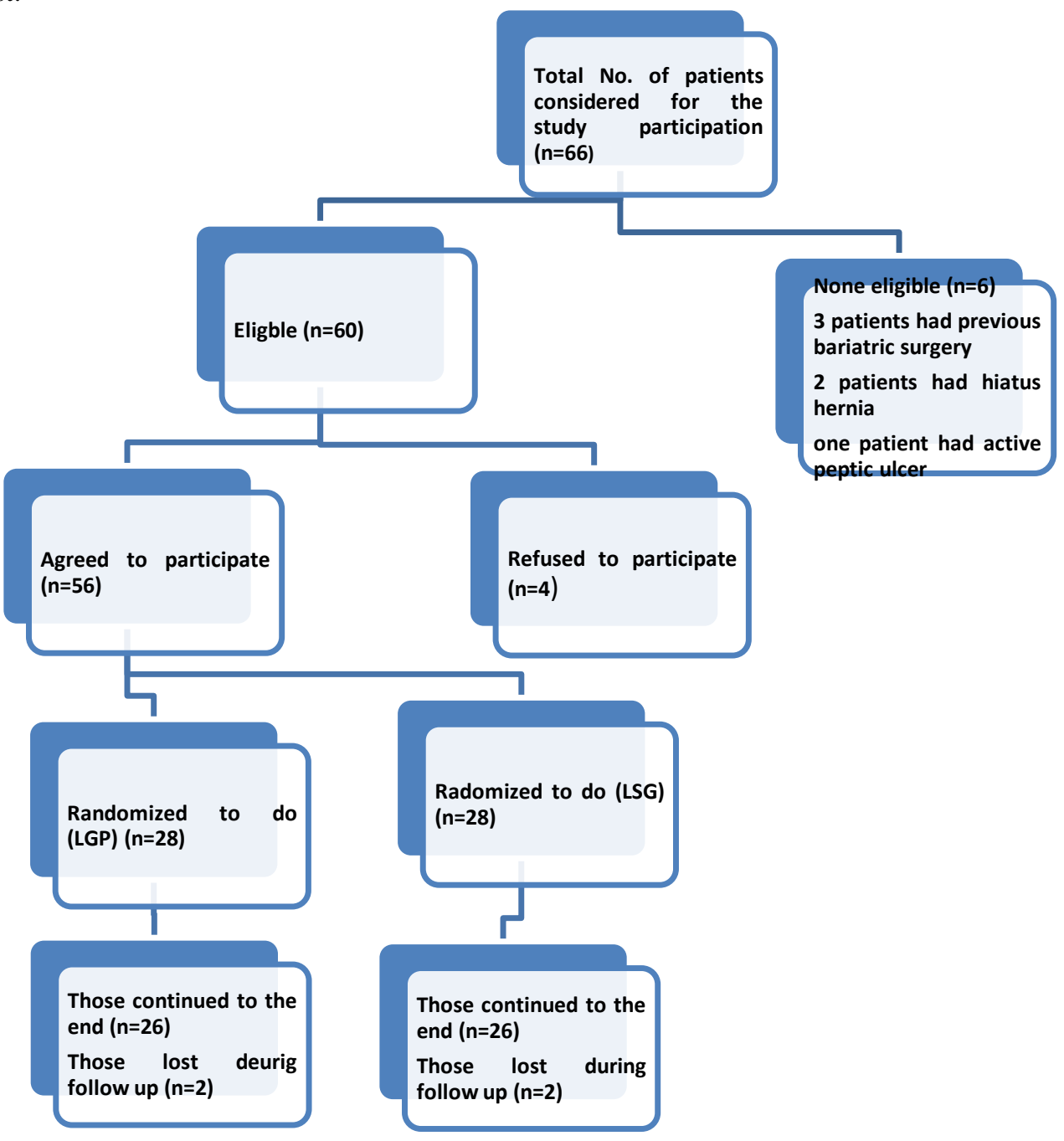

Fig 1:-Trial flow sheet shows progress through the phases of the trial. 


\section{Statistical analysis:}

Data collected and analyzed using SPSS version 20. According to the type of data qualitative represent as number and percentage, quantitative continues group represent by mean $\pm \mathrm{SD}$, the following tests were used to test differences for significance; Differences between frequencies (qualitative variables) and percentages in groups were compared by Chi-square test. Differences between parametric quantitative independent groups by t test, paired by paired t. P value was set at $<0.05$ for significant results.

\section{Results:-}

The mean operative time was 65 (range 60-90) min. for LGP and 60 (range 55-85) min. for LSG, with no statistically significant difference between both. The mean length of hospital stay was 2.5 (range 3-6) days for both groups. There is nausea in12 (46.1\%) patients in LGP but in 2 (7.7\%) in LSG. Vomiting is present in $9(34.6 \%)$ cases in LGP but in $2(7.7 \%)$ in LSG. Two patients had minor gastric leak in (LSG) group post-operatively, both patients were kept NPO, continue on IV fluids, antibiotic and close monitoring to vital signs till this leak stopped. Three patients in (LSG) group and one patient in (LGP) had post-operative bleeding that need blood and plasma transfusion and keep patients on conservative measures with no need for re operation .Two cases of gastric stenosis were occurred in LGP. There is reduction of HbA1c in all patients but more significant in LSG group (mean 1.3 versus 0.6 in LGP group). As regarding hypertension, five out of seven patients improved after LSG whereas two out of three patients improved after LGP. The mean of the BMI decreased significantly from preoperatively (46.96 \pm $4.30)$ to $(32.34 \pm 2.75)$ in LGP group and from $(46.23 \pm 4.21)$ to $(27.19 \pm 4.38)$ in LSG group one year after surgery.

Table 1:-Demographic distribution among studied groups:

\begin{tabular}{|l|c|c|c|c|}
\hline & LGP $(\mathbf{n = 2 6})$ & LSG $(\mathbf{n}=\mathbf{2 6})$ & Test & p-value \\
\hline Age (years) & & & (t) test & \\
Range & $21-48$ & $20-50$ & 0.191 & 0.849 \\
Mean \pm SD & $40.15 \pm 7.35$ & $39.73 \pm 8.53$ & $($ X2) & \\
Sex & $7(26.9 \%)$ & $9(30.8 \%)$ & 0.36 & 0.54 \\
Male & $19(73.1 \%)$ & $17(65.4 \%)$ & & \\
Female & &
\end{tabular}

LGP: Laparoscopic gastric plication. LSG: Laparoscopic sleeve gastrectomy. P-value < 0.05 is significant. SD: standard deviation.

Table 2:-Post-operative outcome:

\begin{tabular}{|l|c|c|c|c|}
\hline & LGP (n=26) & LSG (n=26) & Test & p-value \\
$\mathbf{N}(\mathbf{\%})$ & $\mathbf{N}(\mathbf{\%})$ & $2(7.7 \%)$ & 5.65 & $0.017^{*}$ \\
\hline Nausea & $12(46.1 \%)$ & $2(7.7 \%)$ & 5.65 & $0.017^{*}$ \\
\hline Vomiting & $9(34.6 \%)$ & $2(7.7 \%)$ & 2.08 & 0.14 \\
\hline Gastric leak & 0 & $3(11.6 \%)$ & 1.08 & 0.29 \\
\hline Bleeding & $1(3.8 \%)$ & 0 & 2.08 & 0.14 \\
\hline Gastric stenosis & $2(7.7 \%)$ & (X) & \\
\hline
\end{tabular}

LGP: Laparoscopic gastric plication. LSG: Laparoscopic sleeve gastrectomy. SD: standard deviation. P-value < 0.05 is significant.

Table 3:-Comparison between the two groups as regarding HbA1c and hypertension.

\begin{tabular}{|l|c|c|c|c|}
\hline & LGP $(\mathbf{n = 2 6})$ & LSG $(\mathbf{n = 2 6})$ & p-value & Significance \\
\hline HbA1c (Mean \pm SD) & & & & \\
Before & $6.4 \pm 1.6$ & $6.8 \pm 1.5$ & 0.347 & NS \\
After & $5.8 \pm 1.2$ & $5.5 \pm 0.8$ & 0.418 & NS \\
HbA1c change & $0.6 \pm 0.7$ & $1.3 \pm 0.9$ & 0.006 & HS \\
\hline HTN (N. and \%) & & & & NS \\
Before & $3(11.5 \%)$ & $7(27 \%)$ & 0.168 & NS \\
After & $1(3.8 \%)$ & $2(7.6 \%)$ & 1.00 & NS \\
HTN improvement & $2(7.6 \%)$ & $5(19.2 \%)$ & 0.158 & \\
\hline
\end{tabular}

LGP: Laparoscopic gastric plication. LSG: Laparoscopic sleeve gastrectomy. HTN: Hypertension. SD: standard deviation. HS: high significance. 
Table 4:-BMI distribution in both groups:

\begin{tabular}{|l|c|c|c|c|}
\hline BMI (Mean \pm SD) & LGP $(\mathbf{n = 2 6})$ & LSG $(\mathbf{n = 2 6})$ & (t) Test & p-value \\
\hline Preoperative & $46.96 \pm 4.30$ & $46.23 \pm 4.21$ & -0.618 & 0.539 \\
\hline After a month & $43.11 \pm 3.74$ & $41.50 \pm 4.22$ & -1.459 & 0.151 \\
\hline After 3 month & $39.26 \pm 3.37$ & $36.15 \pm 4.55$ & -2.800 & $0.007 *$ \\
\hline After 6 month & $35.69 \pm 3.18$ & $30.92 \pm 4.02$ & -4.735 & $0.00 * *$ \\
\hline After a year & $32.34 \pm 2.75$ & $27.19 \pm 4.38$ & -5.077 & $0.00 * *$ \\
\hline
\end{tabular}

LGP: Laparoscopic gastric plication. LSG: Laparoscopic sleeve gastrectomy.BMI: body mass index. SD: standard deviation $\mathrm{p}$-value $<0.05$ is significant

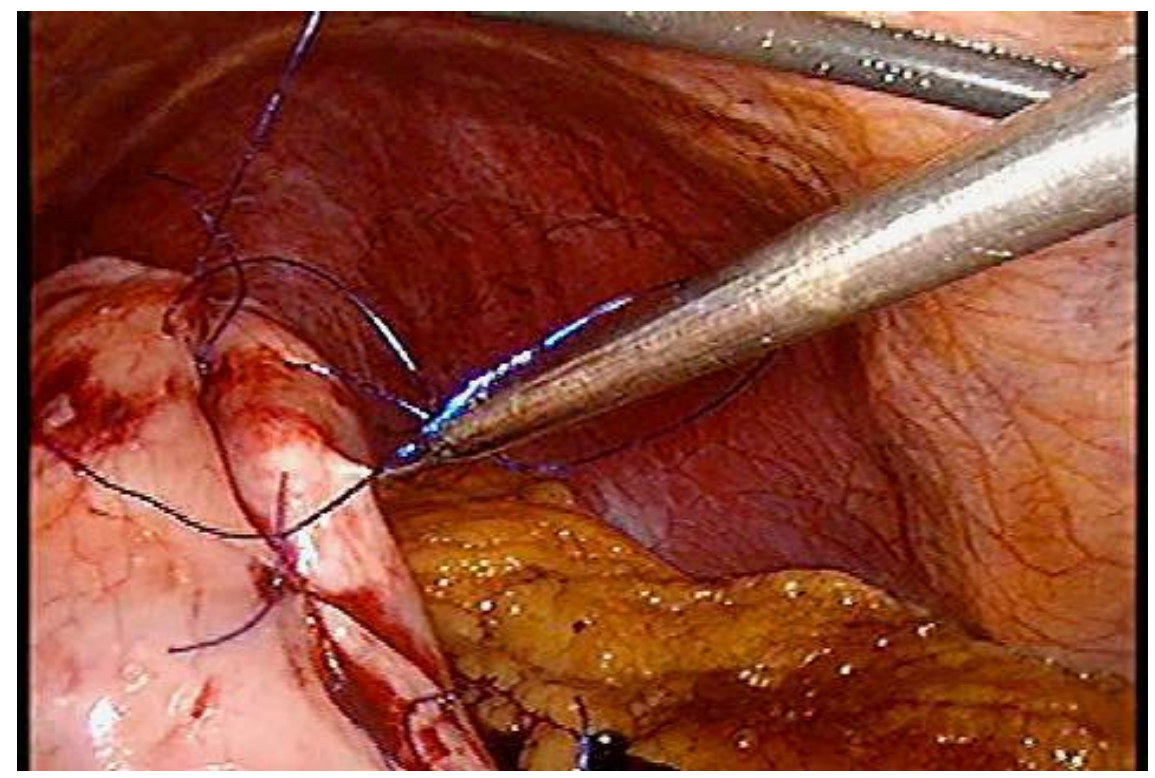

Figure 2:-Taking 1st row of interrupted stitches of stomach.

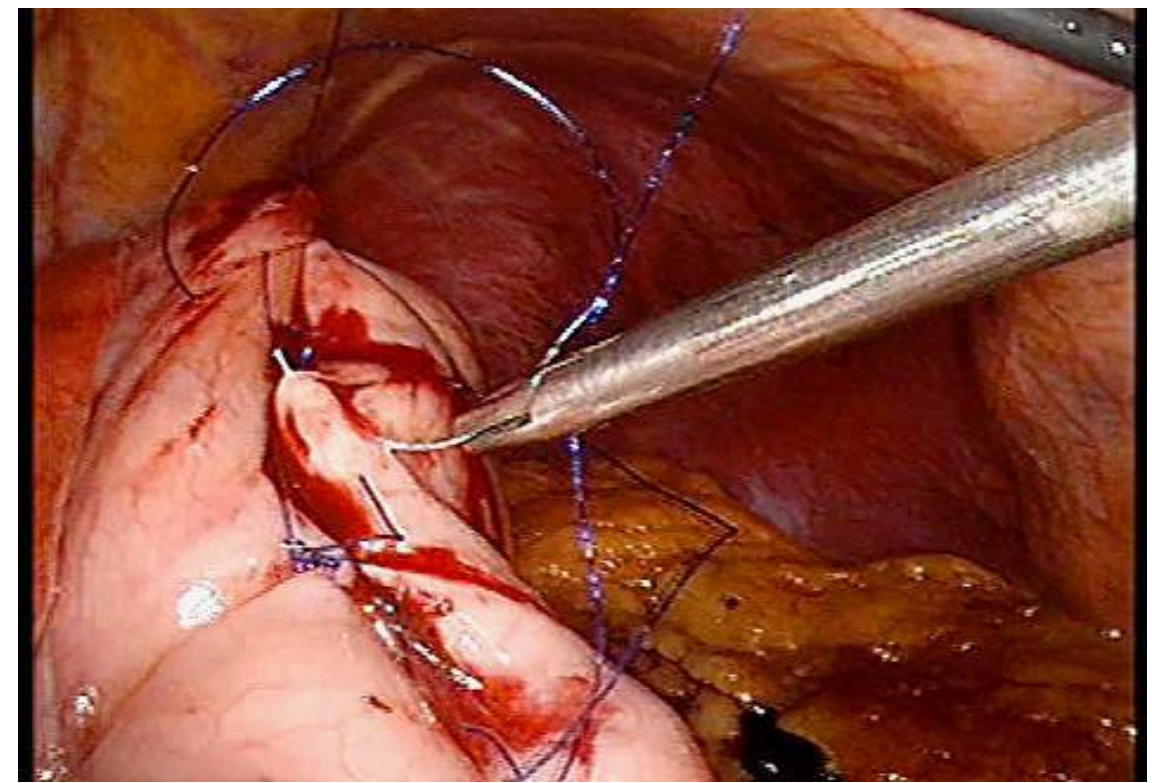

Figure 3:-Taking 2nd row of continuous stitches of stomach. 


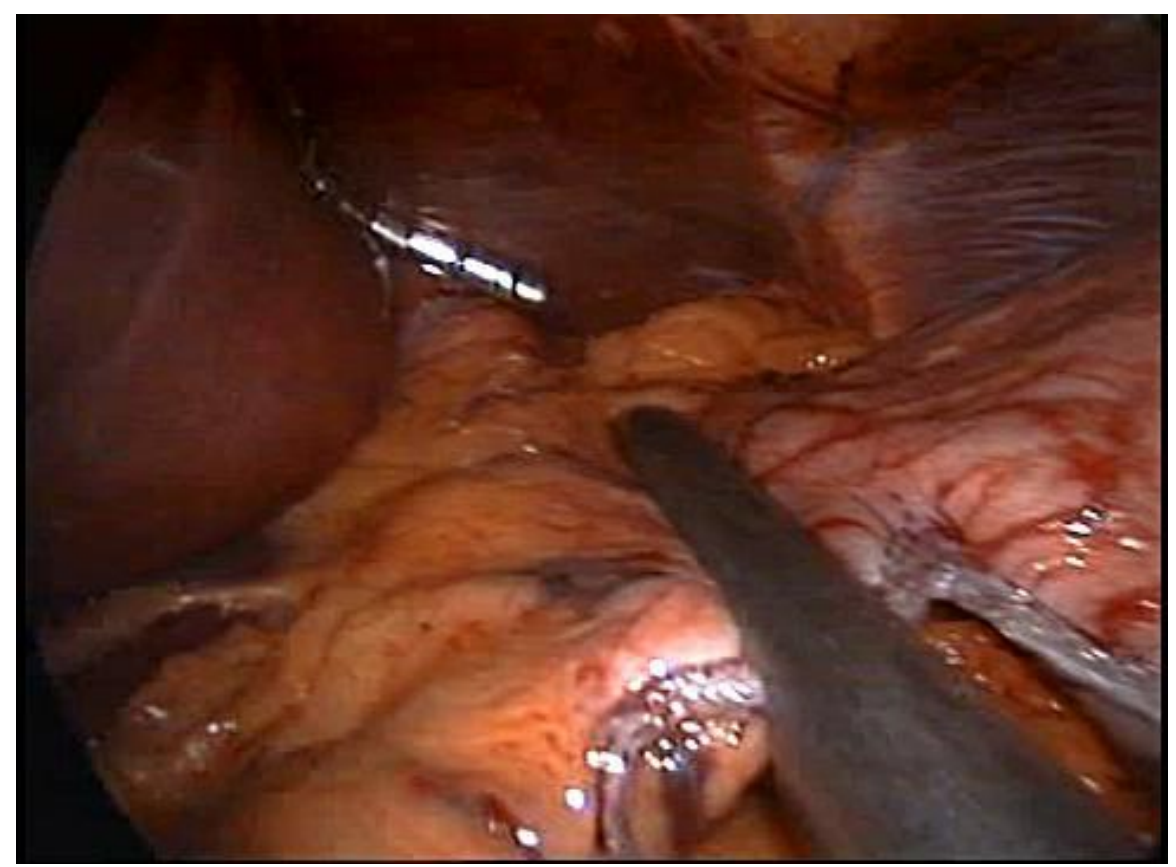

Figure 4:-Using gold cartilage load to cut stomach away from pylorus.

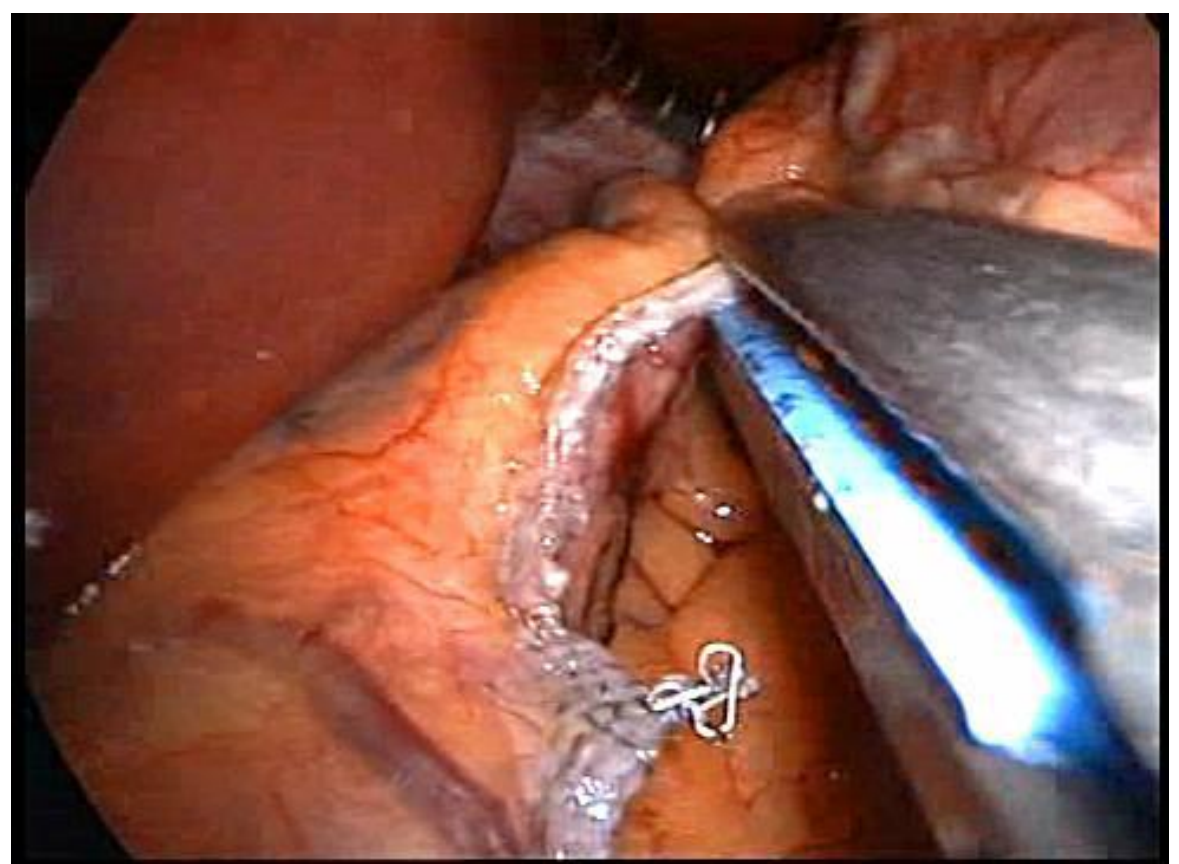

Figure 5:-Using blue cartilage to cut stomach near funds.

\section{Discussion:-}

Bariatric or weight loss surgery is the only treatment for morbid obesity that confers definitive weight loss at long term follow up. In addition to weight reduction there is a strong possibility of amelioration or even cure of various co-morbid conditions associated with obesity ${ }^{5}$.

Laparoscopic Sleeve Gastrectomy (LSG) gained popularity in Egypt due to its technical simplicity and excellent weight loss. However, complications have been seen in LSG owing to its long staple line with potential bleeding or even leakage. Moreover, the irreversible nature of LSG might be less attractive to some patients ${ }^{6}$. 
Laparoscopic Gastric Plication (LGP) bears many advantages but in a developing country like Egypt one of the most appealing features of this kind of surgery is its low cost due to elimination of the use of end staplers. Therefore, morbidly obese patients who cannot afford the price of other costly bariatric surgeries like LSG would not be deprived the benefits of durable weight loss by surgery ${ }^{7}$.

In our study there is improvement of HbA1c in all patients but more significant in LSG group (mean 1.3 versus 0.6 in LGP group). As regarding hypertension, five out of seven patients improved after LSG whereas two out of three patients improved after LGP. This is comparable to the results of some studies ${ }^{8,9,10}$ who reported an improvement of co-morbidities after one year.

The mean operative time in our study for (LGP/LSG) was (65/60) minutes respectively. It was comparable to that reported in some studies ${ }^{11,12,13}$ which recorded $(95 / 85),(91 / 81)$ and $(96 / 89)$ minutes.

In our study nausea were occurred in 12 patients (46.1\%) and vomiting in $9(34.6 \%)$ in LGP but nausea and vomiting occurred in 2 patients $(7.7 \%)$ in LSG which is comparable to Talebpour and his colleagues ${ }^{14}$, where nausea and vomiting occurred in $20 \%$ of LGP and $7.5 \%$ in LSG. In another study by Fried and his colleagues ${ }^{15}$ early postoperative nausea and vomiting occurred in less than one third of patients and symptoms were controlled using antiemetic without prolonged hospital stay.

As regarding gastric leak, it was occurred in 2 patients $(7.7 \%)$ of LSG that managed by conservative measures and no patients in LGP group. This is slightly more than showed by two studies ${ }^{16,17}$ which are $1.4 \%$ and $1.2 \%$ respectively in LSG due to small number in our study. Talebpour and Amoli ${ }^{18}$ showed 2 cases of leak in LGP where both were managed by reoperation by direct suture repair. The possible mechanism of post-operative gastric leak including acute distension of the stomach or sever vomiting with a resultant full-thickness tear at suture line and delayed thermal injury of the stomach that occurred during division of the short gastric vessels, particularly if the attachments to the upper pole of the spleen were very short ${ }^{4}$.

Post-operative bleeding was occurred in one patient in LGP (3.8\%) and in 3 patients in LSG (11.6\%) in our study but Shi and his colleagues ${ }^{17}$ showed $3.6 \%$ hemorrhage after LSG. Hemorrhage occurred in 2 out of 135 patients after LGP in the study done by Skeraks et $\mathrm{al}^{19}$.

Two cases of gastric stenosis in LGP group and no gastric obstruction in both groups of our study but Skeraks and his colleagues ${ }^{19}$ recorded 3 out of 135 patients had acute gastric obstruction after LGP who were treated surgically again. Dijian et al $^{13}$ showed one patient admitted again due to gastric stenosis after LSG.

The mean length of hospital stay of our study was 2.5 days (range 3-6) and this is agree with the study done by Elie

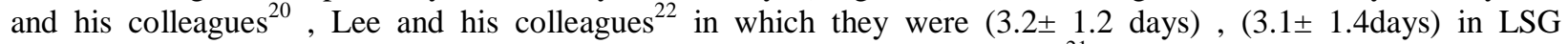
respectively. It is slightly shorter than the study of Andraos and his colleagues ${ }^{21}$ in which it was $(3.9 \pm 1.4)$ days in LGP.

The mean BMI pre-operatively was $(46.96 \pm 4.30)$ of LGP group that decrease to (32.34 \pm 2.75$)$ with a mean reduction of $14.72 \mathrm{~kg} / \mathrm{m}^{2}$ but in LSG group decreased from pre-operatively $(46.23 \pm 4.21)$ to (27.19 \pm 4.38$)$ with a mean reduction of $19.04 \mathrm{~kg} / \mathrm{m}^{2}$ after one year. This our results were found to be close to those reported by Abouzeid and Taha ${ }^{23}$ who reported that the reduction of the mean BMI in(LSG versus LGP) was (14.45/10.35) respectively and Dijian and his colleagues ${ }^{11}$ who reported that the reduction was $(10.3 \pm 2.9 / 7.9 \pm 2.4)$ after one year.

There was no mortality in our study, these results is like the results that published by Pujol et $\mathrm{al}^{24}$.

\section{Conclusion:-}

LGP is feasible, safe, inexpensive and effective, but has an inferior weight-loss effect compared to LSG for morbidly obese patients with BMI above $40 \mathrm{~kg} / \mathrm{m}^{2}$. 


\section{References:}

1. Herron DM (2011): "the surgical management of severe obesity" The amount Sinai Journal of Medicine, 71:6371.

2. Wang Y, Mi Jand Shan XY (2007): "Is China facing an obesity epidemic and the consequences? The trends in obesity and chronic disease in China". Int J Obes (Lond), 31:177-188.

3. Iannelli A, Dainese R, Piche T, Facchiano E and Gugenheim J (2010):"Laparoscopic sleeve gastrectomy for morbid obesity". World J Gastroenterol, 14(6):821-7.

4. Brethauer SA, Harris JL, Kroh M and Schauer PR, (2011): Laparoscopic gastric plication for treatment of severs obesity. Surg Obes Related Dis; 7:15-22.

5. Khwaja H and Bonanomi G (2010): Bariatric surgery: techniques, outcomes and complications. Current Anaesthesia \& Critical Care; 21: 31-38.

6. Baltasar A, Bou R, Bengochea M, Serra C and Cipagauta L (2007) Use of a Roux limb to correct esophagogastric junction fistulas after sleeve gastrectomy. Obes Surg; 17: 1408-1410.

7. ElGeidie AA and El Hak NG (2013): Laparoscopic Gastric Plication in obese Egyptians Patients: technique and initial short-term outcome. Surgery; 3:151.

8. Silecchia G, Boru C, Pecchia A, Rizzello M, Casella G, Leonetti F, and Basso N (2006): Effectiveness of laparoscopic sleeve gastrectomy (first stage of biliopancreatic diversion with duodenal switch ) on comorbidities in super-obese high risk patients.obes surg; 16:1138-1144.

9. Milone L, Strong V and Gagner M(2005): Laparoscopic sleeve gastrectomy is superior to endoscopic intragastric balloon as a first-stage procedure for super-obese patients (BMI $\geq 50)$. Obes Surg; 15(5):612-617.

10. Cottam D, Qureshi F and Mattar S (2006): Laparoscopic sleeve gastrectomy as an initial weight loss procedure for high risk patients with morbid obesity. Surg Endosc; 20:859-922.

11. Dijian Shen, Huan Ye, Yuedong Wang and Wei Li (2013) : comparison of short-term outcomes between laparoscopicgreater curvature plication and laparoscopic sleeve gastrectomy : surg endosc; 27:2768-2774.

12. Broderick RC, Fuchs HF and Harnsberger CR, (2014): Comparison of bariatric restrictive operations: laparoscopic sleeve gastrectomy and laparoscopic gastric greater curvature plication. Surg Technol Int;25:82-9

13. Taha $\mathrm{O}$ (2012). Efficacy of laparoscopic greater curvature plication for weight loss and type 2 diabetes: 1-year follow-up. Obes Surg; 22:1629-32.

14. Talebpour M, Motamedi SM and Talebpour A (2012): Twelve year ex-perience of laparoscopic gastric plication in morbid obesity: devel- opment of the technique and patient outcomes. Ann Surg Innov Res; 6:7. Doi: 10.1186/1750-1164-6-7.

15. Fried M, Dolezalova K and Buchwald JN (2012): Laparoscopic greater curvature plication (LGCP) for treatment of morbid obesity in a series of 244 patients. Obes Surg; 22:1298-307.

16. Sakran N, Goitein D and Raziel A (2012): Gastric leaks after sleeve gastrectomy: a multicenter experience with2.834 patients .Surg Endosc; 27:240-5.

17. Shi X, Karmali S , Sharma AM , and Birch DW (2010): A review of laparoscopic sleeve gastrectomy for morbid obesity . Obes Surg; 20:1171-1177.

18. Talebpour M and Amoli B S (2007). Laparoscopic total gastric vertical plication in morbid obesity. J Laparoendosc Adv Surg Tech; 17:793-8.

19. Skrekas G, Antiochos k and Stafyla VK (2011): Laparoscopic gastric greater curvature plication: results and complications in a series of 135 patients .obese surg; 21:1657-63.

20. Elie Chouillard, Naim Schoucair, Salman Alsabah, Bashaer Alkandari and Jean Biagini (2015): Laparoscopic Gastric Plication (LGP) as an Alternative to Laparoscopic Sleeve Gastrectomy (LSG) in Patients with Morbid Obesity:A Preliminary, Short-Term, OBES SURG; 26:1167-1172.

21. Andraos SA, Ziade D and Achcouty R (2011): Early complications of 120 laparoscopic greater curvature plication procedures. Bariatric Times;8(9):10-15.

22. Lee WJ, Lee KT, Ser KH, Chen JC, Tsou JJ and Lee YC (2015). Laparoscopic adjustable gastric banding (LAGB) with gastric plication: short-term results and comparison with LAGB alone and sleeve gastrectomy. Surg Obes Relat Dis; 11 (1):125-30

23. Abouzeid Mohamed M and Taha Osama (2015): Laparoscopic sleeve gastrectomy versus laparoscopic gastric greater curvature plication: a prospective randomized comparative Study; 24:41-47.

24. Pujol Gebelli J, Garcia Ruiz de Gordejuela A and Casajoana Badia A (2011): (Laparoscopic Gastric Plication: a new surgery for the treatment of morbid obesity). Published by, The McGraw-Hill Companies, New York. Pp. 1834-1890. 